\title{
Gestures of Despair and Hope: A View on Deliberate Self-harm From Economics and Evolutionary Biology
}

\section{Edward H. Hagen}

Department of Anthropology

Washington State University

Vancouver, British Columbia, Canada

hagen@vancouver.wsu.edu

\section{Paul J. Watson}

Department of Biology

University of New Mexico

Albuquerque, NM, USA

pwatson@unm.edu

\section{Peter Hammerstein}

Institute for Theoretical Biology

Humboldt University

Berlin, Germany

p.hammerstein@biologie.hu-berlin.de

\begin{abstract}
A long-standing theoretical tradition in clinical psychology and psychiatry sees deliberate self-harm (DSH), such as wristcutting, as "functional"- a means to avoid painful emotions, for example, or to elicit attention from others. There is substantial evidence that DSH serves these functions. Yet the specific links between self-harm and such functions remain obscure. Why don't self-harmers use less destructive behaviors to blunt painful emotions or elicit attention? Economists and biologists have used game theory to show that, under certain circumstances, self-harmful behaviors by economic agents and animals serve important strategic goals. In particular, "costly signals" can credibly reveal a "private state" in situations where verbal claims and other "cheap" signals might be disbelieved. Here, DSH is scrutinized using signaling theory, and a variant, the theory of bargaining with private information. The social contexts and associated features of DSH suggest that it might be a costly, and therefore credible, signal of need that compels social partners to respond.
\end{abstract}

\section{Keywords}

bargaining, costly signaling, Darwinian medicine, Darwinian psychiatry, deliberate self-harm, honest signaling, parasuicide 
The evolution of cooperation, in many cases, is intimately intertwined with the evolution of signaling systems. The spectacular social systems of ants, for example, are grounded in chemical signaling (Hölldobler 1995). In humans, language might have evolved, in part, to facilitate group coordination (Számadó and Szathmáry 2006), crying probably evolved as a mode of parent-offspring communication (e.g., Furlow 1997), and generous behavior might sometimes be a form of costly signaling (e.g., Gintis et al. 2001; Bird and Smith 2005). Even music could have evolved to play some role in human sociality (e.g., Wallin et al. 2001; Hagen and Hammerstein 2008).

Here we explore whether deliberate self-harm (DSH)deliberate physical self-injury such as wrist-cutting — could be a form of signaling that helps solve one problem of cooperation: determining a mutually beneficial "price" for the goods or services exchanged in a cooperative relationship. When multiple partners provide the same good or service, partner choice and partner switching can establish a price via market mechanisms (Noe and Hammerstein 1994, 1995). When multiple partners do not exist, however, or when partner switching costs are high, prices must be set by other mechanisms. One mechanism, which we explain in detail below, is costly delay, usually studied in models of bargaining with incomplete information (e.g., Kennan and Wilson 1993; Ausubel et al. 2002). We propose that when there is conflict among cooperative partners over "price," and partner switching is not an option, individuals might put the cooperative venture at risk to pressure social partners to make concessions; in some especially serious cases this could involve various forms of self-harm. Because we wish to help build bridges between evolutionary biology and clinical psychology and psychiatry, we describe the basics of DSH that are probably unfamiliar to most evolutionary biologists; conversely, we explain basic aspects of costly signaling and bargaining that are probably unfamiliar to most psychiatrists and clinical psychologists.

\section{Deliberate Self-harm}

Psychiatrists often identify "signaling" as one function of depression, suicidality, and other forms of psychopathology (e.g., Farberow and Shneidman 1961; Henderson et al. 1981), yet these forms of signaling, if indeed they are such, have rarely been analyzed in a strategic signaling framework. Here we examine DSH as a potential bargaining strategy. According to some researchers, DSH can be classified into distinct types based on factors like age of onset, number of episodes, and lethality, and one or more of these types deserve recognition as distinct diagnostic categories, such as a form of axis I impulse control disorder (e.g., Pattison and Kahan 1983; Favazza 1998).

There is increasing dissatisfaction among psychiatrists, however, with a purely descriptive, syndromal approach to
DSH. In order to achieve a deeper understanding of DSH, several researchers have recently advocated synthesizing research on symptoms and risk factors with the long-standing theoretical tradition that sees DSH as "functional," a self-destructive means to some desirable end (e.g., Gratz 2003; Nock and Prinstein 2004; Claes and Vandereycken 2007; Klonsky 2007).

A review of this functional theoretical literature (Suyemoto 1998) extracted six models encompassing four developmental traditions (behavioral and systemic theory, psychoanalytic theory, ego and self-psychology, and object relations). Most models propose that a history of abandonment, conflict, and abuse is the root cause of DSH. These negative experiences are then linked to DSH in various ways. A victim of rape feels shame and self-loathing, for instance, which causes her or him to self-harm. DSH, in turn, either protects the self-harmer from uncomfortable or overwhelming emotions (an intrapsychic function) or it provides secondary gains by expressing these emotions and eliciting attention and other desired reactions from social partners (an interpersonal function).

As we will document here, the facts largely support this emerging consensus. Yet, in important respects, the consensus view is unsatisfying. On the one hand, a functional perspective of DSH implies that DSH delivers key benefits to the selfharmer, albeit at great cost. On the other hand, it is far from clear why certain individuals engage in DSH, rather than any of a myriad of less costly behaviors, to obtain these benefits. Another weakness of the consensus view is that, in most current models, the intrapsychic and interpersonal functions are treated as distinct and only loosely related. A theory unifying both types of functions would be more parsimonious.

We will develop a theoretical model of DSH that reveals why, to achieve certain cooperative ends, self-harm might be necessary. The model will also explain why traumatic events, severe interpersonal conflict, and communication problems are risk factors for DSH. Finally, it will unify the intrapsychic and interpersonal functions of DSH under a single theoretical umbrella. This model, in brief, grounds the venerable view of self-harmful behavior as a "cry for help" (Farberow and Shneidman 1961) in the theory of costly signaling from economics and evolutionary biology (Spence 1973; Zahavi 1975). As we will explicate shortly, DSH, fundamentally, is a credible cry for help.

There are a variety of terms for DSH, including selfmutilation, self-wounding, self-injury, and parasuicide. Synthesizing the views of many researchers, Suyemoto (1998) defines DSH as deliberate physical self-injury that is socially unacceptable, even within general subcultures, and which is often repetitive, resulting in minor-to-moderate harm. DSH is distinguished from indirect self-harm (e.g., drunk driving) and from acceptable mutilation like piercing or tattooing. DSH does not result in grave injury like eye enucleation or selfcastration (which are usually not repetitive and are generally 
associated with psychosis); and it excludes the self-injurious behavior seen in cognitively impaired individuals such as mentally retarded or autistic children. This definition corresponds closely to what Favazza (1998), who reviews the history of the concept, terms superficial/moderate self-mutilation of episodic or repetitive type.

One important consideration is whether or not to include suicidal behavior in the definition. We, along with many researchers, see strong empirical and conceptual links between DSH and suicidality, and numerous studies do not distinguish between suicidal and nonsuicidal self-harm. Nevertheless, much DSH does not involve suicidal intent (e.g., 59\% in the study of Rodham et al. 2004). Further, the motivations for DSH appear to differ between those with and without suicidal intent. M. Z. Brown et al. (2002), for example, found DSH with suicidal intent was more frequently attributed to an effort to make others better off, whereas nonsuicidal DSH was more often intended to express anger, punish oneself, regain normal feelings, and distract oneself. As will become clear, these latter motivations, as well as lack of intent to die, closely dovetail with the thesis developed here.

For these reasons, and because the massive literature on suicidality would overwhelm the discussion, we will focus mainly on studies in which DSH with no suicidal intent plays a central role. Nevertheless, many studies of DSH include individuals with suicidal intent, so suicidality will inevitably appear in the following discussion.

Skin cutting is the most common form of DSH, occurring in $40-70 \%$ of cases, followed by hitting or banging in $21-44 \%$, and burning in 15-35\%; pinching, scratching, and biting also occur in a few percent (Ross and Heath 2002; Klonsky et al. 2003).

Age of onset for DSH is typically between 14 and 24 years of age (Herpertz 1995), and rates are high in clinical populations, ranging from approximately $20 \%$ (Briere and Gil 1998; Joyce et al. 2006) to $35 \%$ in women with eating disorders (Paul et al. 2002) to over 50\% in women with borderline personality disorder (Brodsky et al. 1997). There are few studies of the prevalence of DSH in the general population, but two relatively recent studies, one of the general population (Briere and Gil 1998) and one of an adult, nonclinical population (Klonsky et al. 2003), both found that about $4 \%$ of respondents reported a history of DSH, with less than $1 \%$ engaging in chronic DSH (Klonsky et al. 2003). Community studies of adolescents and college-aged populations uncovered much higher rates, however, ranging from approximately $14 \%$ to $17 \%$ (Ross and Heath 2002; Whitlock et al. 2006). Most studies have not seen significant sex differences in prevalence rates (see Klonsky et al. 2003 and references therein).

There is fairly broad agreement about the phenomenology of DSH. An incident of DSH is typically precipitated by a rela- tionship problem with family or friends, difficulties at school, or a disciplinary crisis, and the individual often reports feeling depressed, anxious, angry, or fearful prior to self-harming (see Rodham et al. 2004 and references therein). Self-harming is usually done in private, frequently by cutting wrists or forearms with a razor blade, and it is mostly spontaneous. In a study of inpatients, Nock and Prinstein (2005) found that prior to self-injury, $78 \%$ contemplated for only a few seconds or not at all.

In most, the act of self-injury dissipates the negative feelings that precipitated it, bringing feelings of relief, release, calm, or satisfaction, although in a few it induces guilt or disgust (see Suyemoto 1998 and references therein). One woman put it thus: "As the blood flows down the sink, so does the anger and the anguish" (Harris 2000: 167).

Though it is conceivable that the pain of DSH distracts sufferers from problems and painful emotions, most self-harmers do not feel any pain during the act (in contrast to accidental injuries, in which they do experience normal pain). In Nock and Prinstein's study, for instance, $80 \%$ of self-harmers reported feeling little or no pain when injuring themselves, despite the fact that only $18 \%$ were using alcohol or other drugs.

DSH has come to be understood by many therapists as a "morbid form of self-help" (Favazza 1998). Drawing upon insights from economics and evolutionary biology, we now develop a theoretical approach that instead frames DSH as a risky yet potentially "rational" form of self-help.

\section{A Strategic View of DSH}

Many biologists have come to the view that rational decisionmaking, individual learning, social learning (cultural transmission), and natural selection-radically different optimizing processes-nevertheless often converge to very similar solutions. Although there are numerous technicalities, when an agent wishes to achieve the "best" outcome in a given situation, these various optimizing processes can all yield $e x$ actly the same strategy. Thus, mathematical models of profitmaximizing economic agents could, potentially, illuminate the learned or evolved behaviors of fitness-maximizing organisms, including behaviors driven by powerful emotions such as fear and anger (e.g., Hammerstein and Selten 1994; Hammerstein 1996; Fudenberg and Levine 1998; Hofbauer and Sigmund 1998; Vincent and Brown 2003; Nowak and Sigmund 2004). This insight has lead to increasingly productive interactions between evolutionary biologists, economists, and other social scientists (Hammerstein and Hagen 2005).

\section{Self-harm in Economics}

Economists long struggled to explain the paradoxical behavior of parties that know they can profit from trade, yet waste a substantial fraction of the profit on costly delays, or worse, 
fail to reach an agreement at all (e.g., Hicks 1932). These self-harmful inefficiencies were typically ascribed to irrational behavior, greed, or confusion. At the conclusion of a strike, for example, parties often lament the wages and output lost to weeks or months of delay when the same contract could have been agreed upon immediately (Kennan and Wilson 1993). Starting with the work of Akerlof (1970), Spence (1973), and Stiglitz (e.g., Rothschild and Stiglitz 1976), economists began to realize that such behavior, which looked like irrationally self-harmful in hindsight, could, ex ante, be rational (i.e., it could optimize outcomes). The breakthrough was recognizing the impact of private information-information known only to one party - on economic interactions between agents with conflicts of interest (private information is also known as asymmetric information and requires the framework of games with incomplete information). In such interactions, the agent with private information often has an economic incentive to deceive his or her trading partners (e.g., by claiming that a product is in better condition than it really is). Spence (1973), in particular, showed that when there are conflicts among parties, costly behaviors can credibly signal private information to others.

The basic idea is that if signals are costly, and ability to pay is private information, the presence of the signal reveals this private information even when there are incentives to deceive. Ownership of a Rolls-Royce, for example, is a credible signal of wealth because only a wealthy person could afford one. To sketch Spence's original example in a way that conveys a bit of the mathematical flavor of this theory, assume, following the simplified treatment in Bowles and Hammerstein (2003), that there are two types of employees in the population: $t_{1}$ is very productive and worth paying a high wage, and $t_{2}$ is very unproductive and only worth paying a low wage. (In the interests of space, the mathematics in this article omits important details such as proofs of existence; please refer to the original sources, or to the cited reviews, for a more complete treatment.) Unfortunately for employers, employee type is private information, and the wage difference is an incentive for type $t_{2}$ to deceptively claim to be of type $t_{1}$. Assume, however, that employers are willing to pay a wage, $b(s)$, that increases with the level of education, $s$, which is public information. The cost of education, $c$, is also an increasing function of $s$, as well as a function of an employee's type, $t: c(s, t)$. For simplicity, let there be two levels of education, a high level, $s_{1}$, and a low level, $s_{2}$. The payoff for a given level of education is then $w(s, t)=b(s)-c(s, t)$. Note that in this model education does not increase productivity!

In order for employers to get their money's worth, it must be in the interest of high-productivity employees, type $t_{1}$, to choose the high level of education, $s_{1}$, and in the interest of low-productivity employees, $t_{2}$, to choose the low level of education, $s_{2}$. This happens when $w\left(s_{1}, t_{1}\right) \geq w\left(s_{2}, t_{1}\right)$ and $w\left(s_{2}, t_{2}\right) \geq w\left(s_{1}, t_{2}\right)$, respectively. These two inequalities imply:

$$
w\left(s_{1}, t_{1}\right)-w\left(s_{2}, t_{1}\right) \geq w\left(s_{1}, t_{2}\right)-w\left(s_{2}, t_{2}\right) .
$$

Substituting $b(s)-c(s, t)$ for $w$ and rearranging terms gives

$$
\Delta c_{t_{2}}=c\left(s_{1}, t_{2}\right)-c\left(s_{2}, t_{2}\right) \geq c\left(s_{1}, t_{1}\right)-c\left(s_{2}, t_{1}\right)=\Delta c_{t_{1}},
$$

where $\Delta c_{t_{1}}$ and $\Delta c_{t_{2}}$ are the comparative cost of $s_{1}$ versus $s_{2}$ for types $t_{1}$ and $t_{2}$,respectively. In other words, for education level to accurately signal an employee's hidden type, the comparative cost of education must be less for high-productivity employees than for low-productivity employees (the intuition is that low productivity types would take much longer to get their degree, thus paying much more in tuition). Under these conditions, low-productivity employees will not choose a high level of education because they actually net more money choosing a low level of education, whereas high-productivity types net more money by paying what is for them the relatively affordable cost of a high level of education. Education level then serves as a credible signal of productivity that employers can rely on to schedule wages. Costly signaling and other insights about the economic role of private information have been so influential that Spence, Akerlof, and Stiglitz were awarded the Nobel Prize in 2001.

\section{Self-harm in Biology}

In the 1970s, biologists faced problems similar to those of economists. First, biologists had documented numerous examples of extravagant, self-harmful displays such as large, cumbersome peacock tails and exhausting bouts of loud roaring by red deer. These displays, which clearly had evolved, nonetheless appeared to significantly impede an animal's ability to survive and reproduce, challenging the theory of natural selection.

Furthermore, unlike in the marketplace where, at least in theory, "truth in advertising" laws could deter deception, in nature there are no such laws. Organisms were therefore usually expected to evolve deceptive signals to outmaneuver competitors (Dawkins and Krebs 1978). Every instance of camouflage or mimicry, traits that are extremely common in plants and animals (Starrett 1993), is an example of deception. It was not clear how honest, credible signals could evolve.

Shortly after Spence proposed that costs could serve to credibly signal private information in economic transactions, Zahavi (1975) proposed that costly displays, which he termed handicaps, could credibly signal private information about, e.g., physical condition, in conflictual interactions between the sexes, predators and prey, and so forth. The logic is the 
same as that put forward by Spence: by evolving a signal whose inherent cost differs by type or condition, organisms can send honest signals to those with whom they have potential conflicts. A large peacock's tail is a credible signal of mate quality, for instance, because only a healthy, fit peacock could afford one. This idea has had as large an impact on evolutionary biology as it has had in economics (for a review of evolutionary biological perspectives on signaling, see Maynard-Smith and Harper 2003).

Biological approaches to parent-offspring conflict even incorporate the idea that offspring might deliberately harm themselves (e.g., by begging strenuously), or threaten to harm themselves (e.g., by attracting predators), to extort more resources from parents, or to signal greater need (e.g., Zahavi 1975, 1977), a hypothesis that is an active focus of theoretical and empirical investigation (e.g., Eshel and Feldman 1991; Godfray 1991, 1995; Bergstrom and Bergstrom 1999; Royle et al. 2002).

\section{DSH as a Costly, and Therefore Credible, Signal of Need}

It has frequently been suggested that suicidality and DSH are attempts to solve problems involving intense distress, in part by serving as "cries for help" (see Linehan et al. 1987 for a brief review). At the same time, because each is so costly, virtually all experts have understandably classified them as pathologies. As we have seen here, however, costs can play an essential role in sending credible signals when there are incentives for deception. This raises the possibility that these costly behaviors might have a strategic logic, an idea briefly discussed in Zahavi and Zahavi (1997: 220-221).

In economics, the costly signaling idea has been applied in numerous domains. Bargaining theory, which applies to labor strikes, among other things, seems particularly suitable as a model for DSH because going on strike serves both as a costly and therefore credible signal of need, as well as an incentive for management to respond to that need.

Hagen $(1999,2003)$ previously argued that depression is a bargaining strategy, or what Watson and Andrews (2002), who independently developed a very similar approach, termed a strategy for "social navigation" or "niche change" (see also Cline-Brown and Watson 2005; Andrews 2006; Hagen and Barrett 2007). Because the empirical findings for DSH differ substantially from depression, the argument requires a different development than does the argument for depression. The behaviors generated by depression, for example, do not lead to feelings of relief, yet DSH usually does; depression, unlike DSH, often involves a loss of interest in virtually all activities; and unlike suicidality, most DSH does not involve an intent to die.

To take advantage of an existing mathematical framework from economics, but at the expense of some oversimplification, here we use Hagen's (2003) bargaining terminology. In a future publication, we will explore some of the implications and insights gained from Watson and Andrew's richer nichechange/social navigation perspective (Watson and Andrews 2002).

Bargaining, which we apply to DSH in the next section, includes costly signaling as an important component, so we first explain how DSH could be a costly, and therefore credible, signal of need. The logic is as follows. When an individual needs help from others (i.e., is relatively powerless to unilaterally improve their own condition), and relations with key social partners are good, "cheap" signals like verbal requests or crying are sufficient to elicit help because the parties trust and care about one another.

When there are severe conflicts with key social partners, however, a costly signal might be required to convince skeptical social partners that the need was genuine and not a deceptive ploy to exploit them. In such cases, a behavior that was inherently less expensive for individuals in genuine need, but more expensive for individuals not in need, could serve as a credible signal of need. DSH is such a behavior.

For individuals whose lives are going well and who are obtaining substantial benefits from their relationships (i.e., not in need), DSH is very costly because it threatens one's health and thus one's ability to generate and obtain benefits. For individuals whose lives are not going well and who are not benefiting from their relationships, on the other hand (i.e., in need), DSH is much less costly because although it similarly threatens one's health, there are fewer benefits to be lost. Thus, only individuals with little to lose, i.e., those genuinely in need, will exhibit DSH because they are the only ones who can afford to do so- these harmful behaviors credibly signal need (see Figure 1).

It is essential for this hypothesis that DSH puts one's ability to generate "life benefits"-what in an evolutionary context would be called "fitness"- at risk. We can be sure that DSH does put fitness at risk because humans and other animals have evolved an elaborate system of pain receptors and learning and avoidance mechanisms specifically to prevent such injuries.

\section{Deliberate Self-harm as Bargaining}

Missing from the simple model illustrated in Figure 1 is any rationale for social partners to provide help. In the basic theory of costly signaling, the signal sender incurs a cost but the signal receiver does not. DSH, however, imposes costs on both the self-harmer (the putative signal sender) as well as on social partners (the putative signal receivers) who depend on the health and productivity of the self-harmer for essential benefits. It is this which provides an incentive to help, and which necessitates turning to the theory of bargaining with private information, a variant of signaling theory, for a more 


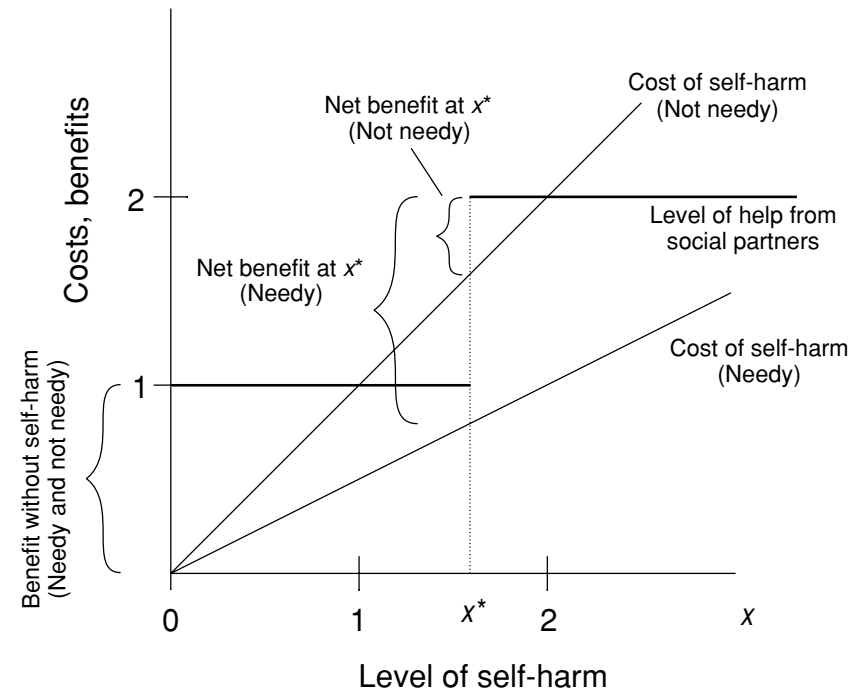

Figure 1.

Simple model of self-harm as a credible signal of need. There are two types in the population: needy and not needy, need being private information. For the needy, the cost of self-harm $=x / 2$, and for the not needy, the cost $=x$. Social partners provide a normal level of help $=1$ to individuals who exhibit levels of self-harm $<x^{*}$, and a high level of help $=2$ to individuals exhibiting levels of self-harm $\geq x^{*}\left(1<x^{*}<2\right)$. Self-harm accurately signals need because needy individuals maximize their net benefit by choosing a level of self-harm $=x^{*}$, whereas not needy individuals maximize their net benefit by choosing a level of self-harm $=0$. After Spence (1973), who used this model in a different context.

complete strategic understanding of DSH. The following sketch of some influential bargaining models in economics, which we map onto DSH, is drawn from a seminal paper by Rubinstein (1982) and the influential reviews of Kennan and Wilson (1993) and Ausubel et al. (2002).

Bargaining refers to situations in which two or more parties can benefit from their relationship, but must first agree on the distribution of the "profit." In the economic realm this describes, e.g., the monetary profit jointly produced by workers and management. In the interpersonal realm, this could describe benefits such as protection, care, and assistance generated by relationships between, e.g., children and parents or wives and husbands.

A key assumption of many bargaining models is that there are costs of delay: the profit from cooperation decreases if cooperation is delayed, usually modeled as a discount factor $\delta, 0 \leq \delta<1$, so that profits decrease as $\delta^{t}$, where $t$ is the number of rounds. This gives each party leverage over the other parties because, by withholding its contribution for a period of time, one party can reduce the total size of the "pie" that is to be divided among all parties-the longer cooperation is delayed, the more profit is lost by all. Analogously, DSH directly jeopardizes an individual's health and well-being, thus jeopardizing the benefits he or she can provide to others. The greater the frequency or severity of self-harm, the greater is the extent to which benefits are put at risk.
If there is no private information, then in a model of alternating offers between two players, there is, with some simplifying assumptions, a straightforward equilibrium result (see Rubinstein 1982 for details). Assume the size of the "pie" is 1 . In round 0 , player A makes an offer $x_{\mathrm{A}} \in[0,1]$ to player $\mathrm{B}$, which $\mathrm{B}$ either accepts or rejects. If $\mathrm{B}$ accepts, $\mathrm{A}$ receives $x_{\mathrm{A}}$ and $\mathrm{B}$ receives $1-x_{\mathrm{A}}$. If $\mathrm{B}$ rejects, then he makes an offer $x_{\mathrm{B}} \in[0,1]$ to $\mathrm{A}$ in round 1 . If $\mathrm{A}$ accepts, $\mathrm{B}$ receives $x_{\mathrm{B}}$ and $\mathrm{A}$ receives $1-x_{\mathrm{B}}$, and so forth. If the players reach an agreement at time $t$, then player $i$ receives $\delta_{i}^{t} x_{i}$, where $\delta_{i}$ is player $i$ 's discount factor.

Assuming that all equilibrium offers are accepted, and that players always make the same offer in equilibrium, then for player $\mathrm{B}$ the value of rejecting an offer $x_{\mathrm{A}}^{*}$ is $\delta_{\mathrm{B}} x_{\mathrm{B}}^{*}$ (the discounted value of his subsequent offer to $\mathrm{A}$ ). This implies that in equilibrium

$$
1-x_{\mathrm{A}}^{*}=\delta_{\mathrm{B}} x_{\mathrm{B}}^{*},
$$

that is, A must offer to B exactly the discounted value of what B would, in the next round, request for himself. Similarly

$$
1-x_{\mathrm{B}}^{*}=\delta_{\mathrm{A}} x_{\mathrm{A}}^{*} .
$$

Substituting, we have

$$
\begin{aligned}
& x_{\mathrm{A}}^{*}=\frac{1-\delta_{\mathrm{B}}}{1-\delta_{\mathrm{A}} \delta_{\mathrm{B}}} \\
& x_{\mathrm{B}}^{*}=\frac{1-\delta_{\mathrm{A}}}{1-\delta_{\mathrm{A}} \delta_{\mathrm{B}}} .
\end{aligned}
$$

If both players have the same discount factor $\delta$, then in round 0 player A offers

$$
\frac{1}{1+\delta}
$$

which $\mathrm{B}$ accepts immediately. If $\delta=0$ (i.e., the pie is worthless after round 0), A keeps the entire pie for himself, which (by our assumption) $\mathrm{B}$ accepts, demonstrating a first mover advantage for A. As $\delta \rightarrow 1$, then, in the limit, A must offer $1 / 2$ to $\mathrm{B}$ in round 0 because $\mathrm{B}$ can wait forever, demonstrating that bargaining power equates with an ability to wait.

A key point is that because the size of the pie and discount factors are common knowledge (i.e., not private information), A knows exactly how much he has to offer B in order to get $\mathrm{B}$ to accept in round 0 ; this is the essence of our derivation above. Consequently, there is no delay in reaching an agreement.

If, on the other hand, the players do not know the value of the relationship to others-either the discount factors and/or the valuations are private information-then it is difficult for 
parties with conflicts of interest to agree on a mutually beneficial distribution of the profit because, to gain a greater share, each has an incentive to deceptively understate the value of cooperation. If player A did not know what the value of the pie was for player $B$ in the above example, he would not know how much to offer in round 0 in order to get $B$ to accept. Nor could he simply ask $B$ because $B$ has an incentive to understate the value of the pie so that $A$ believes he must offer a larger fraction of it to B to get B to accept. In the real world, to get a raise workers might deceptively complain that they are not earning enough, whereas management might deceptively complain that the company is not making enough profit to raise wages. Interpersonally, children might deceptively claim they need more care and protection than they really do, whereas parents might deceptively claim that they have no ability to increase levels of care and protection.

A central insight of models of bargaining with private information is that the costs of delay are less for those who are genuinely profiting less. (Mathematical models of bargaining with private information are too complex to sketch here, so we proceed verbally; for detailed examples, see Kennan and Wilson 1993; Ausubel et al. 2002.) In our example, if A's offer leaves too little for B, B will net more profit by rejecting the offer and making his own offer in the next round despite the fact that the pie is shrinking. In the real world, underpaid workers have an incentive to go on strike because, by garnering a sufficiently increased share of the profits, they can more than compensate for the (small) salaries lost during the strike. Overpaid management, on the other hand, has no incentive to go on strike because any (relatively smaller) increased share of the profit could not compensate for the (large) salaries that would be lost during a strike. Going on strike is thus a credible, or unfakeable, signal that wages are too low in the same way, as we have argued DSH could be a credible signal of need.

Unlike the simple costly signaling described in the previous section, however, in bargaining the signaling can go in both directions. Because the pie is shrinking, overpaid management has an incentive to increase wages just enough so that workers cannot do better by waiting longer, and so start working again, to everyone's benefit. Analogously, DSH puts relationship benefits at risk, providing an incentive to social partners who value the relationship to respond with increased help before the self-harmer inflicts additional, debilitating selfharm. If management makes no offer to increase wages after an extended period of time, this is a credible signal to the workers that management has no extra profit to share (because if they did, they would profit more by offering a wage increase immediately, rather than letting the pie shrink further). Similarly, if social partners do not respond to DSH, this credibly signals their low valuation of the relationship.

Another key difference between simple costly signaling and bargaining is that for bargaining to work, switching part- ners must usually be difficult or impossible-otherwise, partners could simply cooperate with someone else, as is the case when management can easily hire replacement workers. It is also worth emphasizing that parties only make and accept offers that are in their interest; if an offer is accepted, a mutually beneficial agreement has been reached.

Withholding —or putting at risk-the benefits one provides to a cooperative venture is at once a credible signal that one is not profiting sufficiently from the current arrangement, a threat to others' benefits that compels them to negotiate over terms (an "extortionary" function), and an implicit signal that, despite conflict, a mutually beneficial arrangement may be possible.

A young woman being sexually molested by her stepbrother, for example, might complain to her mother and stepfather that she needs protection. But, if there are conflicts between the daughter and her parents, the daughter might not be believed-perhaps she is selfishly trying to drive a wedge between her parents and the step-brother. Her true level of need is private information. The daughter's subsequent self-harmful behavior would be an attempt to convince her parents that her need for protection is genuine, and to compel them to intervene on her behalf. If the daughter's well-being is highly important to the parents, they will intervene quickly and effectively, and DSH should cease. If they do not intervene, or only offer an insufficient increase in care and protection, the daughter now has credible information that she is less valuable to her parents than she hoped. She might then engage in the analogue of repeated rounds of bargaining: repeated episodes of self-harm, perhaps of increasing severity.

\section{Evidence in Support of DSH as a Bargaining Strategy}

\section{DSH in Small, Interdependent Communities}

Unlike psychiatrists and clinical psychologists, anthropologists typically spend years living in small, highly interdependent communities, in exactly the same social conditions in which bargaining should be found when conflicts of interest arise. As participants in community life, they have had the opportunity to observe the social context and strategic semantics of self-harm that most researchers in the West have not had. Indeed, it is widely recognized in many of these societies that DSH and suicidality are often means to signal hurt and anger. According to Hezel (1984), a Jesuit priest who has specialized in ethnographic research on suicide and self-harm, the Trukese (a Micronesian society) even have a special term for this strategy, amwunumwun. Hezel's description of both DSH and suicidality closely resembles the bargaining model, and it is worth quoting him at length (Hezel 1984: 200-201):

In a situation like that which usually precedes suicide, one in which a person is hurt and angered by someone he loves and respects, Trukese commonly use a strategy that they call amwunumwun. The refusal 
of a boy to eat when his parents have offended him is an example of amwunumwun; another is the openly promiscuous conduct of a girl who, in anger at her parents' conduct, "goes to the beach" to signal her feelings. A young man who wishes to protest some demand of his father-such as, in one actual case, his request to enjoy sexual relations with his son's wife-may stab himself in the arm or inflict other injury upon himself. Amwunumwun, therefore, is a strategy of withdrawal or self-abasement used to show those one must both love and obey that one is hurt by them. The act of amwunumwun is intended not principally to inflict revenge-although it would be naive to maintain that there is nothing of this in the act-but to dramatize one's anger, frustration, and sorrow in the hope that the present unhappy situation will soon be remedied. If the one who employs amwunumwun is trying to shame the one who has offended him it is always with the intention of showing the offending party the sad state into which their relationship has fallen so that he will take steps to restore it to what it once was or should have been.

Suicide, in the overwhelming majority of Trukese cases, and quite possibly those in other parts of Micronesia as well, must be understood as a kind of amwunumwun. Indeed, it is the extreme form of amwunumwun since it means inflicting the ultimate harm upon oneself in order to compel the parents or others to recognize the harm they have done and to repair it. This type of suicide can be, paradoxically, a gesture of both despair and hope at one and the same time.

Hezel goes on to explain that even if the relationship cannot be saved in the here and now, then at least there is a possibility that it might be salvaged beyond the grave because, although "the victim's life may have been a constant struggle with his family," his death "will change everything and guarantee that he is restored to his former rightful place in their eyes." This is one point where our analysis differs from Hezel's: We believe that DSH and suicidality are always attempts to improve the relationship in the here and now. Unfortunately, these strategies might not always succeed.

Although DSH and suicidality are heterogeneous phenomena, many cases in the ethnographic record conform to the bargaining model. In a study among the Aguaruna (a group of hunter-horticulturalists who live in the uplands of the Amazon in northern Peru), M. F. Brown (1986: 311) concluded: "Some segments of Aguaruna society—specifically, women and young men who are unable to organize collective responses to conflict-use solitary acts of violence directed against the self to express anger and grief, as well as to punish social antagonists."

Giddens (1964: 116), in a concise review of the ethnographic literature on suicidality, similarly concluded: "In all of these examples, the suicidal act is a recognized type of social mechanism, an accepted method of bringing pressure to bear upon others."

\section{Need and Conflict}

Communities in Western societies are not as interdependent as those found in small-scale, kin-based societies, yet inter- dependent relationships still characterize nuclear families and tightly-knit peer groups, where conflicts are common but unilaterally imposing changes or switching partners is often difficult or impossible (Hagen 2003).

Many of the basic facts about DSH in Western societies support a signaling or bargaining function in families and other personal relationships. Under the bargaining hypothesis, selfharmers have important, unmet needs, but conflicts with key social partners are preventing these needs from being recognized and addressed. There is ample evidence of this in the family histories of self-harmers.

In a review of parasuicide, Linehan (1981) found that, compared to nonsuicidal patients and the general population, parasuicides' interpersonal environments are fraught with difficulty, hostility, and interpersonal conflict. Studies have also found that self-harmers are more likely to come from families characterized by divorce, neglect, and parental deprivation. Webb (2002) conducted a systematic review of the literature on the psychosocial factors ${ }^{1}$ in DSH among adolescents that employed strict inclusion criteria (studies were excluded based on lack of original data, poor reporting or discrimination of details, or nonrelevant outcome measures). Most studies included both suicidal and nonsuicidal individuals, and none distinguished clearly between the two categories.

Webb found that, compared to controls, self-harming adolescents had significantly more problems with family, friends, romantic partners, and school. School problems tended to involve bullying and not academics, although pressure to achieve and achievement failure were also factors. DSH adolescents did not feel more criticized by their parents, but they did feel less well understood, an issue to which we shall return. Additional discriminating factors included sexuality, feelings of past violation, family suicidality and illness, personal loss, family conflict, and friend suicidality. Factors that protected against DSH included family intactness and cohesion, with cohesion being more important when the family was no longer intact. Webb concluded that family problems in combination with external social pressures play an important role in DSH.

Childhood trauma, particularly sexual abuse, is strongly correlated with DSH later in life. In a comprehensive review of the literature from 1988 to 1998 on the relationship between child abuse, self-harm, and suicidality (29 studies in all), Santa Mina and Gallop (1998) found that there were more reports of self-harm, suicidal ideation, and suicidal behavior in clinical and community populations of adults who reported sexual and/or physical abuse in childhood than in comparison groups who did not report abuse. Four of the studies focused on DSH in abused and nonabused samples. Although overall rates of DSH varied widely between studies, childhood abuse typically increased DSH rates by factors of 1.5 to 4 , or more (e.g., from $48 \%$ to $77 \%$, or from $12 \%$ to $50 \%$ ). 
Sexual abuse and trauma in childhood could be an index of current problems in the family, including an unmet need for protection. Consider that many instruments designed to assess childhood sexual and physical abuse measure events up to the age of 16, and participants in studies of DSH are often young adults (e.g., Gratz et al. 2002). This means that the childhood abuse of some self-harmers in these studies might have been in the recent-rather than the distant—past, or is even ongoing.

\section{Communication Problems}

Another central prediction of the bargaining model is that costly DSH is only required to communicate need when "cheap" signals of need like complaining and crying would not be believed. It is therefore worthwhile to more closely examine the communication problems that figure prominently among adolescents exhibiting DSH. In a study of 52 adolescents presenting to a hospital emergency department for self-harm (including both suicidal and nonsuicidal individuals) versus hospital-based matched controls, Tulloch et al. (1997) found that lack of a family confidant and poor parentadolescent communication were very strongly correlated with self-harm, even after controlling for numerous other variables. The odds ratio for self-harm among adolescents with little open communication with their fathers, for example, was 8.1; after controlling for other variables, it ranged from 2.4 to 6.7, depending on the control variable (it was smallest after controlling for interpersonal tensions and strains owing to health care and finances). For adolescents in the upper quintile of poor communication scores with their fathers, the odds ratio for self-harm was 99.7 (albeit with wide confidence intervals).

Individuals exhibiting DSH are in the crosshairs: they have more family problems, more problems outside the family, and are more likely to have suffered child abuse. Yet they cannot easily communicate their needs to those who should be their most important caregivers and protectors. Under these conditions, a means to credibly signal need and compel change is a virtual necessity.

\section{Gains From DSH}

If, at least some of the time, DSH does not deliver tangible interpersonal benefits to self-harmers that outweigh the obvious costs, the bargaining model is false. However, we cannot emphasize the following point too strongly: the point of bargaining is not to elicit sympathy, concern, pity, compassion, goodwill, or any comparable emotion. Workers who go on strike are not trying to elicit any of these from management. Rather, they are trying to convince management that wages are too low and are trying to compel an increase in salary or other concessions from powerful others who are, at best, reluctant to provide them, and will frequently be actively hostile. Yet if management's own income depends on the workers' labor, management will often have no choice but to yield to the workers' demands.

Under the bargaining hypothesis, the same goes for DSH. The proposed goal of DSH is to convince social partners with whom the self-harmer has grave conflicts that the self-harmer has real, unmet needs, and to compel advantageous relationship changes. If, along the way, DSH garners sympathy or concern, so much the better, but, under the hypothesis, it is equally likely to generate anger and hostility. In interdependent relationships, social partners will nonetheless often have no choice but to make changes beneficial to the self-harmer if they wish to extract any benefits from the relationship at all.

Fortunately for the hypothesis, there is evidence that DSH elicits benefits. Many theorists, for instance, believe that secondary gains (i.e., interpersonal benefits) reinforce DSH. Suyemoto (1998: 538) summarizes some of this literature:

The attention and concern of others can be powerful reinforcers of behavior. In Offer and Barglow's study, self-mutilating patients included attention and social status among peers (as a result of being able to endure pain) as two reasons for self-mutilating behavior. Other authors have emphasized the secondary gains of attention and control over others. Chowanec and his colleagues see one of the primary goals of self-mutilation as mobilizing others to react. [Citations in text omitted.]

A presumption of these reinforcement models is that the perceived value of secondary gains outweighs the costs of DSH. Under the bargaining model, this is only true for individuals with critical, unmet needs and severe conflicts with important social partners. The bargaining model thus explains why most of the population does not engage in DSH.

\section{Self-reported Reasons for DSH}

Self-reports from adolescents confirm that interpersonal benefits are an important goal of DSH. Self-reported reasons can be divided into two categories: intrapsychic (e.g., depression or anxiety) and interpersonal. Intrapsychic reasons are the most frequently endorsed, and we will discuss those in a moment, but interpersonal reasons are also frequently endorsed, and they strongly support the bargaining model.

The bargaining model does not predict that individuals would necessarily have any conscious awareness of the interpersonal functions of DSH. In fact, many evolutionists argue that individuals should generally deceive themselves so as to better manipulate others (Alexander 1979; Slavin 1985; Trivers 1985; Nesse 1990). Nevertheless, self-harmers often admit to motives consistent with signaling to, or bargaining with, social partners (see Table 1).

DSH researchers occasionally downplay signaling or strategic functions of DSH, perhaps because they are justifiably worried that these would stigmatize individuals who selfharm as "manipulative." The word "manipulative," however, 
Table 1. All reasons for DSH endorsed by participants in Rodham et al. $2004(N=220)$ and Nock and Prinstein $2004(N=89)$. Participants could endorse multiple reasons. Two frequently endorsed interpersonal reasons, marked below with [†], are interpretable as signaling need; most other interpersonal reasons revolve around eliciting desired reactions from others.

\begin{tabular}{lll}
\hline Rodham et al. & \multicolumn{1}{c}{ Reason } \\
\hline Intrapsychic & I wanted to get relief from a terrible state of mind & I wanted to punish myself \\
& I wanted to die & 39 \\
& Show how desperate I was feeling & 34 \\
Interpersonal & I wanted to find out if someone really loved me & 24 \\
& I wanted to get some attention & 18 \\
& I wanted to frighten someone & 16 \\
& I wanted to get my own back &
\end{tabular}

Nock and Prinstein

Intrapsychic

Interpersonal

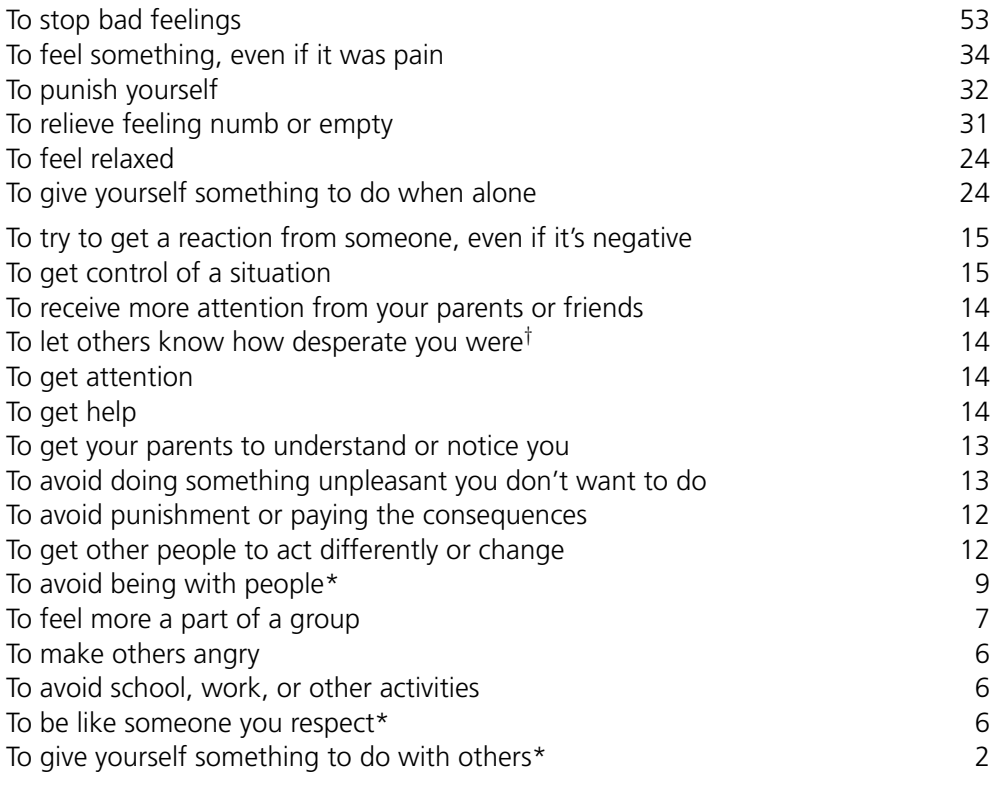

*Not clearly consistent with the bargaining model.

connotes a conscious but unfair or insidious means to a personally advantageous end. In contrast, in the bargaining model DSH is a necessary, often unconscious, means to a potentially mutually beneficial end. We therefore prefer the term "strategic" to "manipulative."

Nearly all of the interpersonal reasons for DSH endorsed by self-harmers can be readily interpreted as signaling or bargaining strategies. In a large $(N=5737)$ community study of English adolescent students, for example, 220 students reported an incident of self-cutting in the preceding year (Rodham et al. 2004); 34\% had suicidal intent. Among other measures, self-harmers were asked to select motives from a list of eight, three of which were intrapsychic, and five of which were interpersonal (more than one motive could be chosen). As can be seen in Table 1, each of the interpersonal motives functions to either signal distress (e.g., "Show how desperate I was feeling"), elicit benefits (e.g., "I wanted to get some attention"), or to impose costs on others (e.g., "I wanted to frighten someone"), as the bargaining model requires.
In a similar study of adolescent psychiatric inpatients ( $N=89$ ) referred for self-injurious behavior or thoughts, Nock and Prinstein (2004) developed and validated a fourfactor model of DSH. Two factors were intrapsychic and two were interpersonal. The two interpersonal factors comprised 16 reasons, 12 of which were social-positive reinforcement, such as "To get help" or "To get attention," and four of which were social-negative reinforcement, such as "To avoid doing something unpleasant you don't want to do." All of the items are listed in Table 1, and most interpersonal items again function to either signal distress, elicit benefits (including avoiding onerous tasks), or to impose costs on others (three exceptions

Motives that aim to elicit negative reactions from others, such as "To try to get a reaction from someone, even if it's negative" and "To make others angry," might seem to contradict the bargaining model, as does evidence that DSH can arouse intense, negative reactions in others (see Gratz 2003 and references therein). After all, shouldn't positive responses are marked with an asterisk). 
from social partners always be desired? No. As emphasized above, a costly strategy like DSH is only required when there is conflict with social partners, and those partners could easily resent a hardball bargaining strategy. Although bargaining can lead to outcomes that are ultimately for the benefit of all, it nonetheless often forces one or more parties to make concessions, and this will frequently cause the affected parties to react negatively.

We turn now to intrapsychic states, the most frequently endorsed reasons for DSH. Their importance to DSH is to be expected. Many adaptive behaviors are driven by emotions, desires, and other intrapsychic states. If you ask someone why they are eating, they would probably say, "because I'm hungry," not "because my body required energy." If you asked why they had sex, although many might offer interpersonal reasons such has to have a baby or feel close to someone, most would also probably say "because it feels good" or "to feel relaxed." Intrapsychic states should similarly motivate bargaining.

Table 1 lists all the intrapsychic reasons endorsed by selfharmers in both Rodham et al.'s and Nock and Prinstein's studies. All these reasons are consistent with the bargaining hypothesis. Being in a "terrible state of mind" is understandable for people with important, unmet needs who have severe conflicts with social partners; under the bargaining hypothesis, harming oneself as a means to relieve this state is analogous to eating to relieve hunger. Having a desire to "punish" oneself is, of course, very close to having a desire to harm oneself, an unsurprising sentiment for someone about to engage in DSH. Feeling "numb or empty" is close to depression, which we argue is also a bargaining strategy (Watson and Andrews 2002; Hagen 2003), and to feel "relaxed" is simply a positive motive to self-harm.

\section{The Functions of DSH Across Studies}

Klonsky (2007) conducted a meta-analysis of 18 empirical studies of DSH functionality. These studies included inpatient, outpatient, general and psychiatric hospital, forensic, and nonclinical populations, and used one or more of three methodologies: self-reported reasons for DSH, self-reports of the phenomenology of DSH (i.e., general descriptions of reasons for DSH by self-harmers, but not in reference to instances of their own self-harm), and laboratory studies using proxies for self-harm (e.g., measuring emotional arousal in patients who are visualizing self-harm). From these 18 studies Klonsky distilled seven potential functions of DSH: affect-regulation, antidissociation, antisuicide, interpersonal boundaries, interpersonal influence, self-punishment, and sensation-seeking.

The pattern of functions ascribed to DSH across studies was quite similar to the pattern revealed in the two studies described above. All 18 studies found support for intrapsychic functions. Support for an affect-regulation function (to alleviate acute negative affect or affective arousal) was especially strong. Modest-to-strong support for an antidissociation function (e.g., to generate feelings, even if negative) was also found in the 10 studies that examined it.

But there was clear and consistent support, as well, for an interpersonal-influence function of DSH. This function was found across inpatient, outpatient, general and psychiatric hospital, and nonclinical populations, and across two methodologies: self-reported reasons for DSH and self-reports of DSH phenomenology. Although it was endorsed by a majority of patients only in one study, all of the 10 studies that examined an interpersonal-influence function found support for it.

\section{Behavioral Studies}

Direct observations of DSH eliciting interpersonal benefits would obviously provide strong support for the bargaining model. For infants and children who exhibit self-injurious behavior (SIB), primarily by head-banging, but also by biting, hitting, scratching, and other means, there is excellent observational evidence that these behaviors elicit responses from parents, which, in turn, reinforce the behaviors.

The prevalence of SIB in infants aged 9-18 months is $15 \%$, and $9 \%$ in two-year-olds (Kurtz et al. 2003 and references therein). Behavioral studies show that SIB is largely socially maintained, either by social-positive reinforcementthe provision of favored stimulus such as attention, food, or toys - or by social-negative reinforcement- the removal of an aversive stimulus such as escape from an onerous task. Kurtz et al. (2003), for example, found that in a sample of young children (10 months to 5 years old) referred for SIB, $48 \%$ of SIB was socially maintained, mostly by social-positive reinforcement. Similar results have been found in older children and adults with mental retardation. In a referred sample of mentally retarded individuals ranging from 1 to 50+ years of age, Iwata et al. (1994) found that social reinforcement was a determinant of SIB in over two thirds of the sample.

Unfortunately, it is not clear whether these results support the bargaining model. On the one hand, the model strongly predicts that children should bargain using DSH. Children require enormous investment from caregivers, yet they are fairly powerless. They cannot switch parents, physically threaten them, or unilaterally impose conditions on their relationship. There is intrinsic conflict between parents and children over levels of investment because parents might need to allocate investment to siblings or other tasks (Trivers 1974). And by harming themselves, children are making a direct threat to parents' biological fitness.

On the other hand, most (but not all) of the children in these studies were suffering mental retardation and other cognitive deficits and developmental delays. Although it could be argued that such children would be especially likely to have unmet needs and conflicts over levels of investment from parents, it could equally well be argued that SIB is a pathological 
consequence of the underlying cognitive problem (that is why we've chosen to label these behaviors as SIB rather than DSH). Though we do not dismiss the relevance of these results, especially because some studies have included cognitively unimpaired children, neither can we invoke them in support of the bargaining model until much more is known about SIB in the general population of infants and children.

\section{Forensic Populations}

The forensic literature on DSH and suicide attempts contains frank discussion of manipulative or, as we would prefer to term it, strategic intent (e.g., Haycock 1989; Groves 2004). As Haycock (1989: 85) puts it:

There is ... a sociological logic to the suspicions of manipulation in jail suicide attempts. With the label "danger to self" can go relief from the obligations of the imprisoned. Behavior that mimes the suicidal can win transfer from a jail to a health service unit, forensic or other hospital. Nowhere else except in [the] military are the secondary gains of nonfatal self-injury presumed to be as strong. Jail or prison self-harm appears to present the manipulative component of suicide attempts in its purest form.

The supposition seems to be that in prisons, low-level DSH is purely manipulative, whereas life-threatening suicide attempts are not. In the bargaining model, however, it is exactly the genuine risk to well-being that underpins the strategy because this risk guarantees that those who are not in genuine need cannot afford to use it. And indeed, recent studies of DSH and suicidality in forensic settings confirm that measures of manipulative intent do not discriminate between low-level and life-threatening self-harm. Dear et al. (2000) found, for example, that 12 of 18 suicide attempts that were categorized as manipulative were nonetheless moderately or highly serious attempts (as assessed by a standard instrument), and 3 of the 18 posed a moderate or high risk to life (as assessed by nursing staff).

\section{Objections to the Bargaining Model}

The strongest evidence against the bargaining model is the clear correlation of DSH with psychopathology. This suggests that DSH is also psychopathological and therefore does not have a "rational," strategic function. As discussed earlier, rates of DSH are significantly elevated in clinical populations, and, in DSM-IV, DSH is a symptom of borderline personality disorder. In a population survey of young adults, Skegg et al. (2004) found at least one DSM-IV disorder in $100 \%$ of those exhibiting more severe self-harm (ICD-9 self-harm, including suicide attempts), $65 \%$ of those exhibiting less severe DSH, and $36 \%$ of those exhibiting no self-harm behaviors.

This evidence is less damaging to the bargaining model than it seems. First, DSH often occurs in the absence of other psychopathology. In the less severe self-harm category in
Skegg et al.'s study (the one closest to the DSH definition used here), although $65 \%$ had a DSM-IV disorder, $35 \%$ did not. As Skegg et al. themselves note,

Health professionals often encounter young men in crisis with suicidal or self-harmful thoughts but no evidence of psychiatric illness. This finding suggests that they are wise to take such thoughts seriously and offer support, even though there may be no illness to treat. (p. 194)

Much DSH cannot be explained as a consequence of psychiatric illness.

Second, a large fraction of the psychopathology found in self-harmers comprises depression and substance dependence (60\% of those exhibiting ICD-9 self-harm had a mood disorder, as did $22 \%$ of those exhibiting less severe DSH). It has been argued elsewhere that unipolar depression is also a bargaining strategy (e.g., Watson and Andrews 2002; Hagen 2003), so this association is not surprising under the bargaining hypothesis. In fact, it actually strengthens the use of a common theoretical framework for depression and DSH. The association of DSH with substance dependence is also not surprising. Alcohol and other drugs are often used to dull emotional pain, and alcohol might even reduce inhibitions against self-harm, strengthening this association.

Finally, people with psychopathology have unmet needs too. It could be argued that the mentally ill are more likely to have unmet needs and greater conflicts with key social partners than the population at large, and thus a greater likelihood of using costly behaviors to signal these needs and elicit care.

If DSH functions, in part, as a signal, then it is necessary that social partners know about it. Cuts on exposed areas of the body, such as wrists (a commonly used location) are obviously quite visible. But cuts and injuries elsewhere might not be. In a large prospective study of a representative Finnish birth cohort where DSH was measured by the item "I deliberately try to hurt or kill myself," parent-child agreement on DSH was low (Sourander et al. 2006), suggesting that parents did not know about their children's DSH. At age 15, 38 girls admitted to DSH, but only 6 parents agreed (16\%), and 9 boys admitted to DSH, but only 2 parents agreed (22\%). (Parentchild agreement about the absence of DSH was high, roughly $90 \%$ for both sexes).

In another recent study (Hawton and Rodham 2006), however, $80 \%$ of teenaged self-harmers reported that someone knew about their DSH. These results are more consistent with the fact that a relatively large minority of self-harmers admit to interpersonal motives. One possible resolution of this apparent contradiction is that adolescent self-harmers might often not be signaling parents, but members of their peer group, including romantic partners. Another possibility is that self-harmers are deliberately hiding their injuries from parents. Crying is obviously an evolved signal, yet it is not uncommon to consciously override its signaling function, e.g., by crying alone. 
Many adaptive signals and behaviors, such as the behavioral manifestations of anger, jealousy, and sadness, can be consciously overridden or concealed if desired. The same could be true of DSH. Some self-harmers admit to a tension between concealing and revealing DSH, with attention-seekers being seen as less "legitimate." As one young woman put it (Crouch and Wright 2004: 193):

... if you're self-harming you're doing it for yourself, not to put it on show. But then that's why people do it, 'cos they want attention, so I suppose you got to let people know somehow.

More research on this topic is clearly needed.

Another challenge to the bargaining hypothesis is the fact that laboratory animals also exhibit DSH. In one study, about $25 \%$ of laboratory raised, individually housed rhesus macaques engaged in self-directed biting and $11 \%$ in self-inflicted wounding (Lutz et al. 2003). The bargaining hypothesis assumes a complex social structure where individual benefits depend on highly interdependent cooperative relationships. It is conceivable that rhesus macaques, animals with a highly complex social organization involving cooperative relationships, have evolved a bargaining strategy involving self-injury, but this possibility is remote. Much more likely is that the self-injury seen in rhesus monkeys is a pathological response to living and maturing alone in a small cage. Supporting this interpretation, Lutz et al. found that individual housing at an early age and for an extended period of time were both important risk factors for self-injurious behavior in rhesus monkeys.

These observations imply that DSH in humans could simply be a pathological response to severe stressors and abnormal living conditions. Yet such a conclusion would be premature. The living condition of these monkeys is extremely abnormal. It is true that the experiences of many people exhibiting DSH are horrific (e.g., sexual abuse), but they are still not comparable to spending one's entire life in a small cage. Furthermore, unlike in humans, DSH among rhesus monkeys was strongly associated with self-directed stereotypies, such as digit sucking and saluting (placing a finger or hand into or near the eyes). ${ }^{2}$ Lutz et al. speculate that this might be caused by a lack of social contact. Although this challenge to the bargaining model cannot be dismissed, on current evidence DSH in lab animals and humans appears to be qualitatively different.

\section{Testing the Bargaining Hypothesis}

The principal claim here is that DSH is a bargaining strategy. Testing this claim is challenging but fairly straightforward. First, the joint occurrence of the following four conditions must be strongly implicated in the etiology of DSH: (a) the experience of a severe need, inequity, or cost in (b) interdependent social relationships with (c) substantial conflicts of interest, and (d) a relative lack of power to unilaterally improve one's condition. If DSH is widely found in other circumstances, the bargaining model is falsified. Second, key social partners must know about the self-harm. If most incidents of self-harm are hidden, the bargaining model is falsified. Third, DSH must, at some point, cause the social partners of a self-harmer to infer that he or she is suffering a severe need, inequity, or cost. If social partners rarely make such an inference, the bargaining model is falsified. Fourth, DSH must, at least some of the time, cause social partners to help the self-harmer or make beneficial changes despite conflicts in their relationship. If such help or changes are rarely forthcoming, the bargaining model is falsified. Fifth, once sufficient help is forthcoming, DSH should cease. If, in most cases, DSH continues despite provisioning of substantial benefits by key social partners, the bargaining model is falsified.

Assuming the strategic nature of DSH has been established, the following issue then arises: which optimizing process-e.g., natural selection, individual learning, social learning (cultural transmission), or pure rational thoughtproduced DSH? Because this issue is secondary to the central argument that DSH is strategic, we will only briefly sketch an approach to this problem. If DSH is a human universal and involves specialized psychological mechanisms, then natural selection might have played an important role. The fact that self-harmers do not feel pain when they cut themselves, for example, hints at specialized mechanisms for DSH. If, on the other hand, DSH in most individuals develops out of, e.g., experiences of help in response to accidental injuries, then individual learning could be the main optimizing process. If DSH is usually a copycat phenomenon, social learning takes center stage. Of course, each of these processes, along with some rational deliberation, as seems to occur in forensic populations, might be necessary to adequately explain the appearance of DSH in all cases.

\section{Concluding Remarks}

Life is a game that is played for keeps, and the stakes can be very high indeed. A bargaining strategy could therefore involve powerful emotions and other psychological states that ruthlessly cause an individual to put at risk her own well-being and thus the benefits she provides to social partners. These states would be triggered when an individual is in need, her power to make changes unilaterally is limited, and her social partners are uncertain whether she is truly in need and/or they are reluctant to help her. DSH appears to have this bargaining function in small-scale societies. In the West, it is strongly associated with severe social conflict and communication problems; a substantial fraction of self-harmers admits to strategic, interpersonal motives; and there is a widespread conviction among clinicians and theorists that DSH elicits benefits as secondary gains. 
There are obviously many parallels between existing models and the bargaining model, especially in the etiological significance of conflict, the importance of expressing this conflict, and in the secondary gains elicited by DSH (Suyemoto 1998). The approach of Linehan and colleagues comes particularly close. Dialectical Behavior Therapy (DBT; Linehan 1987), a promising and influential clinical approach to DSH exhibited by, especially, those suffering borderline personality disorder, emphasizes the important role problem solving deficits and emotional dysregulation play in DSH. Problem solving deficits are likely to lead to life problems that cause intense suffering. According to DBT, DSH can reduce the emotional pain associated with such intense suffering, it can alleviate the depersonalization, tension, and other forms of emotional dysregulation often caused by trauma such as incest and rape, and it can influence others in ways that alleviate suffering. For example, Ivanoff et al. (2001) say, “[P]arasuicide may also indirectly serve to reduce painful emotions through interpersonal problem-solving. Communication of emotional pain to others may result in validation of that pain, and demonstration of the severity of problems may elicit help or maintain a valued relationship [citations in the original omitted]."

Despite close parallels, the bargaining model stands apart from existing models in three distinct ways. First, the bargaining model explains why such a costly signal is needed to communicate need: when there are severe conflicts of interest, "cheap" signals like crying or verbal requests for help or change will often be discounted or ignored. Because only individuals in genuine need can "afford" to engage in DSH, DSH serves as an unfakeable signal of need. By putting the benefits of social relationships at risk, DSH then compels interdependent partners to respond. Hence, the cost of DSH, counterintuitively, is the key strategic feature of DSH.

Second, whereas in many theories intrapsychic and interpersonal functions have little relationship to one another, under the bargaining model the intrapsychic functions exist to serve the interpersonal functions. Third, although the bargaining model sees DSH as harmful and well worth treating, it does not see DSH as a brain dysfunction, and the focus is not on the putative psychopathology of the self-harmer. DSH is not, for example, a disorder of impulse control (e.g., Pattison and Kahan 1983; Favazza 1998). In the bargaining model, the focus is on genuine unmet needs, real and perhaps intractable conflict, and the ability of DSH to credibly communicate these needs to others in a sometimes-fruitful attempt to obtain essential benefits that would otherwise not be forthcoming. Under the bargaining hypothesis, DSH is a "rational" aspect of human psychology.

Favazza (1998) cites Walsh and Rosen (1988) on the necessity of correcting "maladaptive thoughts" such as "Only through [self mutilation] will other people understand my suf- fering." We argue, in contrast, that this is exactly the function of DSH, and that, in a strategic sense, it is not maladaptive, but adaptive.

\section{Notes}

1. Psychological factors were examined too, but are not discussed here.

2. Some cognitively impaired individuals do exhibit both SIB and stereotypies.

\section{Acknowledgments}

Many thanks to Paul Andrews, Andy Thomson, Nicole Hess, and Jeanne Bracker for their valuable comments based, in part, on talks at the Human Behavioral and Evolution Society Annual Meeting, Berlin, July 2004, and the Medicine and Evolution Symposium, York, December 2006.

\section{References}

Akerlof G (1970) The market for lemons: Qualitative uncertainty and the market mechanism. Quarterly Journal of Economics 84: 488-500.

Alexander RD (1979) Darwinism and Human Affairs. Seattle: University of Washington Press.

Andrews PW (2006) Parent-offspring conflict and cost-benefit analysis in adolescent suicidal behavior: Effects of birth order and dissatisfaction with mother on attempt incidence and severity. Human Nature 11: 190-211.

Ausubel LM, Cramton P, Deneckere RJ (2002) Bargaining with incomplete information. In: Handbook of Game Theory with Economic Applications, Vol. 3 (Aumann RJ, Hart S, eds), 1897-1945. Amsterdam: North Holland.

Bergstrom CT, Bergstrom TC (1999) Does mother nature punish rotten kids? Journal of Bioeconomics 1: 47-72.

Bird RB, Smith EA (2005) Signaling theory, strategic interaction, and symbolic capital. Current Anthropology 46: 221-248.

Bowles S, Hammerstein P (2003) Does market theory apply to biology? In: Genetic and Cultural Evolution of Cooperation (Hammerstein P, ed), 153-165. Cambridge, MA: MIT Press.

Briere J, Gil E (1998) Self-mutilation in clinical and general population samples: Prevalence, correlates, and functions. American Journal of Orthopsychiatry 68: 609-620.

Brodsky BS, Malone KM, Ellis SP, Dulit RA, Mann JJ (1997) Characteristics of borderline personality disorder associated with suicidal behavior. American Journal of Psychiatry 154: 1715-1719.

Brown MF (1986) Power, gender, and the social meaning of Aguaruna suicide. Man (New Series) 21: 311-328.

Brown MZ, Comtois KA, Linehan MM (2002) Reasons for suicide attempts and nonsuicidal self-injury in women with borderline personality disorder. Journal of Abnormal Psychology 111: 198-202.

Claes L, Vandereycken W (2007) Self-injurious behavior: Differential diagnosis and functional differentiation. Comprehensive Psychiatry 48: 137-144.

Cline-Brown K, Watson PJ (2005) Investigating major depressive disorder from an evolutionary adaptationist perspective: Fitness hindrances and the social navigation hypothesis. In: Focus on Depression Research (Devito JT, ed), 15-44. Hauppauge, NY: Nova Science Publishers.

Crouch W, Wright J (2004) Deliberate self-harm at an adolescent unit: A qualitative investigation. Clinical Child Psychology and Psychiatry 9: 185-204.

Dawkins R, Krebs JR (1978) Animal signals: Information or manipulation? In: Behavioural Ecology (Krebs JR, Davies NB, eds), 282-309. Oxford: Blackwell.

Dear GE, Thomson DM, Hills AM (2000) Self-harm in prison: Manipulators can also be suicide attempters. Criminal Justice and Behavior 27: 160-175. 
Eshel I, Feldman MW (1991) The handicap principle in parent-offspring conflict: Comparison of optimality and population-genetic analyses. American Naturalist 131: 167-185.

Farberow NL, Shneidman ES (1961) The Cry for Help. New York: McGraw-Hill.

Favazza AR (1998) The coming of age of self-mutilation. Journal of Nervous and Mental Disease 186: 259-268.

Fudenberg D, Levine K (1998) The Theory of Learning in Games. Cambridge, MA: MIT Press.

Furlow FB (1997) Human neonatal cry quality as an honest signal of fitness. Evolution and Human Behavior 18: 175-193.

Giddens A (1964) Suicide, attempted suicide, and the suicide threat. Man 64: $115-116$.

Gintis H, Smith E, Bowles S (2001) Costly signaling and cooperation. Journal of Theoretical Biology 213: 103-119.

Godfray HCJ (1991) Signalling of need by offspring to their parents. Nature 352: $328-330$.

Godfray HCJ (1995) Signaling of need between parents and young: Parentoffspring conflict and sibling rivalry. American Naturalist 146: 1-24.

Gratz KL (2003) Risk factors for and functions of deliberate self-harm: An empirical and conceptual review. Clinical Psychology: Science and Practice 10: 192-205.

Gratz KL, Conrad SD, Roemer L (2002) Risk factors for deliberate self-harm among college students. American Journal of Orthopsychiatry 12: $128-140$.

Groves A (2004) Blood on the walls: Self-mutilation in prisons. Australian and New Zealand Journal of Criminology 31: 49-64.

Hagen EH (1999) The functions of postpartum depression. Evolution and Human Behavior 20: 325-359.

Hagen EH (2003) The bargaining model of depression. In: Genetic and Cultural Evolution of Cooperation (Hammerstein P, ed), 95-123. Cambridge, MA: MIT Press.

Hagen EH, Barrett HC (2007) Perinatal sadness among Shuar women: Support for an evolutionary theory of psychic pain. Medical Anthropology Quarterly 21: 22-40.

Hagen EH, Hammerstein P (in press). Did Neanderthals and other early humans sing? Seeking the biological roots of music in the territorial advertisements of primates, lions, hyenas, and wolves. Musicae Scientiae.

Hammerstein P (1996) Darwinian adaptation, population genetics and the streetcar theory of evolution. Journal of Mathematical Biology 34: 511-532.

Hammerstein P, Hagen EH (2005) The second wave of evolutionary economics in biology. Trends in Ecology and Evolution 20: 604-609.

Hammerstein P, Selten R (1994) Game theory and evolutionary biology. In: Handbook of Game Theory, Vol. 2 (Aumann RJ, Hart S, eds), 929-993. Amsterdam: Elsevier.

Harris J (2000) Self-harm: Cutting the bad out of me. Qualitative Health Research 10: 164-173.

Hawton K, Rodham K (2006) By Their Own Young Hand. London: Jessica Kingsley Publishers.

Haycock J (1989) Manipulation and suicide attempts in jails and prisons. Psychiatric Quarterly 60: 85-98.

Henderson S, Byrne DG, Duncan-Jones P (1981) Neurosis and the Social Environment. New York: Academic Press.

Herpertz S (1995) Self-injurious behavior: Psychopathological and nosological characteristics in subtypes of self-injurers. Acta Psychiatrica Scandinavica 91: 57-68.

Hezel FX (1984) Cultural patterns in Truckese suicide. Ethnology 23: 193-206.

Hicks JR (1932) The Theory of Wages. London: Macmillan.
Hofbauer J, Sigmund K (1998) Evolutionary Games and Population Dynamics. Cambridge: Cambridge University Press.

Hölldobler B (1995) The chemistry of social regulation: Multicomponent signals in ant societies. Proceedings of the National Academy of Sciences USA 92: 19-22.

Ivanoff A, Brown M, Linehan MM (2001) Dialectical behavior therapy for impulsive self-injurious behaviors. In: Self-injurious Behaviors: Assessment and Treatment (Simeon D, Hollander E, eds), 149-173. Washington, DC: American Psychiatric Press.

Iwata BA, Pace GM, Dorsey MF, Zarcone JR, Vollmer TR, Smith RG, Rodgers TA, Lerman DC, Shore BA, Mazaleski JL, Goh H, Cowdery GE, Kalsher MJ, McCosh KC, Willis KD (1994) The functions of self-injurious behavior: An experimental-epidemiological analysis. Journal of Applied Behavior Analysis 27: 215-240.

Joyce PR, McKenzie JM, Mulder RT, Luty SE, Sullivan PF, Miller AL, Kennedy MA (2006) Genetic, developmental and personality correlates of self-mutilation in depressed patients. Australian and New Zealand Journal of Psychiatry 40: 225-229.

Kennan J, Wilson R (1993) Bargaining with private information. Journal of Economic Literature 31: 45-104.

Klonsky ED (2007) The functions of deliberate self-injury: A review of the evidence. Clinical Psychology Review 21: 226-239.

Klonsky ED, Oltmanns TF, Turkheimer E (2003) Deliberate self-harm in a nonclinical population: Prevalence and psychological correlates. American Journal of Psychiatry 160: 1501-1508.

Kurtz PF, Chin MD, Huete JM, Tarbox RSF, O'Connor JT, Paclawskyj TR, Rush KS (2003) Functional analysis and treatment of self-injurious behavior in young children: A summary of 30 cases. Journal of Applied Behavior Analysis 36: 205-219.

Linehan MM (1981) A social-behavioral analysis of suicide and parasuicide: Implications for clinical assessment and treatment. In: Depression: Behavioral and Directive Intervention Strategies (Glazer H, Clarkin J, eds), 229-294. New York: Garland Press.

Linehan MM (1987) Dialectical behavior therapy: A cognitive behavioral approach to parasuicide. Journal of Personality Disorders 1: 328-333.

Linehan MM, Camper P, Chiles JA, Strosahl K, Shearin E (1987) Interpersonal problem solving and parasuicide. Cognitive Therapy and Research 11: $1-12$.

Lutz C, Well A, Novak M (2003) Stereotypic and self-injurious behavior in rhesus macaques: A survey and retrospective analysis of environment and early experience. American Journal of Primatology 60: 1-15.

Maynard-Smith J, Harper D (2003) Animal Signals. New York: Oxford University Press.

Nesse R (1990) The evolutionary functions of repression and the ego defenses. Journal of the American Academy of Psychoanalysis 18: 260-285.

Nock MK, Prinstein MJ (2004) A functional approach to the assessment of self-mutilative behavior. Journal of Consulting and Clinical Psychology 12: $885-890$.

Nock MK, Prinstein MJ (2005) Contextual features and behavioral functions of self-mutilation among adolescents. Journal of Abnormal Psychology 114: 140-146.

Noe R, Hammerstein P (1994) Biological markets: Supply and demand determine the effect of partner choice in cooperation, mutualism and mating. Behavioral Ecology and Sociobiology 35: 1-11.

Noe R, Hammerstein P (1995) Biological markets. Trends in Ecology and Evolution 10: 336-339.

Nowak MA, Sigmund K (2004) Evolutionary dynamics of biological games. Science 303: 793-799.

Pattison EM, Kahan J (1983) The deliberate self-harm syndrome. American Journal of Psychiatry 140: 867-872. 
Paul T, Schroeter K, Dahme B, Nutzinger DO (2002) Self-injurious behavior in women with eating disorders. American Journal of Psychiatry 159: $408-411$.

Rodham K, Hawton K, Evans E (2004) Reasons for deliberate self-harm: Comparison of self-poisoners and self-cutters in a community sample of adolescents. American Academy of Child and Adolescent Psychiatry 43: 80-87.

Ross S, Heath N (2002) A study of the frequency of self-mutilation in a community sample of adolescents. Journal of Youth and Adolescence 31: $67-77$.

Rothschild M, Stiglitz J (1976) Equilibrium in competitive insurance markets: An essay on the economics of imperfect information. Quarterly Journal of Economics 90: 629-649.

Royle NJ, Hartley IR, Parker GA (2002) Begging for control: When are offspring solicitation behaviours honest? Trends in Ecology and Evolution 11: 434-440.

Rubinstein A (1982) Perfect equilibrium in a bargaining model. Econometrica 50: $97-110$.

Santa Mina EE, Gallop RM (1998) Childhood sexual and physical abuse and adult self-harm and suicidal behaviour: A literature review. Canadian Journal of Psychiatry 43: 793-800.

Skegg K, Nada-Raja S, Moffit TE (2004) Minor self-harm and psychiatric disorder: A population-based study. Suicide and Life-threatening Behavior 34: 187-196.

Slavin MO (1985) The origins of psychic conflict and the adaptive function of repression: An evolutionary biological view. Psychoanalysis and Contemporary Thought 8: 407-440.

Sourander A, Aromaa M, Pihlakoski L, Haavisto A, Rautava P, Helenius H, Sillanpää M (2006) Early predictors of deliberate self-harm among adolescents: A prospective follow-up study from age 3 to age 15. Journal of Affective Disorders 93: 87-96.

Spence M (1973) Job market signaling. Quarterly Journal of Economics 81: $355-374$.
Starrett A (1993) Adaptive resemblance: A unifying concept for mimicry and crypsis. Biological Journal of the Linnean Society 48: 299-317.

Suyemoto KL (1998) The functions of self-mutilation. Clinical Psychology Review 18: 531-554.

Számadó S, Szathmáry E (2006) Selective scenarios for the emergence of natural language. Trends in Ecology and Evolution 21: 555-561.

Trivers RL (1974) Parent-offspring conflict. American Zoologist 14: 249264.

Trivers RL (1985) Social Evolution. Menlo Park, CA: Benjamin/Cummings.

Tulloch AL, Blizzard L, Pinkus Z (1997) Adolescent-parent communication in self-harm. Journal of Adolescent Health 21: 267-275.

Vincent T, Brown B (2003) Evolutionary Game Theory, Natural Selection, and Darwinian Dynamics. Cambridge: Cambridge University Press.

Wallin NL, Merker B, Brown S (2001) The Origins of Music. Cambridge, MA: MIT Press.

Walsh BW, Rosen P (1988) Self-mutilation: Theory, Research and Treatment. New York: Guilford.

Watson PJ, Andrews PW (2002) Toward a revised evolutionary adaptationist analysis of depression: The social navigation hypothesis. Journal of Affective Disorders 12: 1-14.

Webb L (2002) Deliberate self-harm in adolescence: A systematic review of psychological and psychosocial factors. Journal of Advanced Nursing 38: 235-244.

Whitlock J, Eckenrode J, Silverman D (2006) Self-injurious behaviors in a college population. Pediatrics 111: 1939-1948.

Zahavi A (1975) Mate selection: A selection for a handicap. Journal of Theoretical Biology 53: 205-214.

Zahavi A (1977) Reliability in communication systems and the evolution of altruism. Evolutionary Ecology (Stonehouse B, Perrins CM, eds), 253-259. London: Macmillan.

Zahavi A, Zahavi A (1997) The Handicap Principle: A Missing Piece of Darwin's Puzzle. Oxford: Oxford University Press. 